\title{
The Key Role of Psychosocial Risk on Therapeutic Outcome in Obese Children and Adolescents. Results from a Longitudinal Multicenter Study
}

\author{
Markus Röbla Martin de Souzab ${ }^{b}$ Ralf Schiel ${ }^{c}$ Ines Gellhaus ${ }^{d}$ \\ Karl Zwiauere Reinhard W. Holl ${ }^{b}$ Susanna Wiegand ${ }^{f}$ \\ ${ }^{a}$ Department of Pediatrics and Pediatric Neurology, University Medical Center Göttingen, \\ Göttingen, ${ }^{b}$ Institute of Epidemiology and Medical Biometry, University of Ulm, Ulm, \\ ${ }^{c}$ Medigreif-Island-Clinic, Heringsdorf, dSt. Vincenz Krankenhaus, Klinik für Kinder- und \\ Jugendmedizin, Paderborn, Germany, ${ }^{e}$ Department of Pediatrics, Landesklinikum, St. \\ Poelten, Austria, ${ }^{f}$ Department of Pediatric Endocrinology and Diabetology, Charité \\ Universitätsmedizin Berlin, Berlin, Germany
}

\author{
Key Words \\ Childhood obesity · Pediatric cohort - Psychosocial risk factors - Therapeutic outcome . \\ Gender · Education
}

\begin{abstract}
Objective: Childhood obesity is high on the global public health agenda. Although risk factors are well known, the influence of social risk on the therapeutic outcome of lifestyle intervention is poorly examined. This study aims to investigate the influence of migration background, low education, and parental unemployment. Methods: 62,147 patients participated in multidimensional lifestyle intervention programs in 179 pediatric obesity centers. Data were collected using standardized software for longitudinal multicenter documentation. 12,305 (19.8\%) attended care for 6-24 months, undergoing an intensive therapy period and subsequent follow-ups for up to 3 years. A cumulative social risk score was calculated based on different risk indicators. Results: Migration background, low education, and parental employment significantly influenced the outcome of lifestyle intervention. The observed BMI-SDS reduction was significantly higher in the subgroup with low social risks factors ( $\triangle$ BMI-SDS $-0.19)$ compared to those presenting moderate $(\triangle \mathrm{BMI}-\mathrm{SDS}-0.14)$ and high social risk $(\triangle \mathrm{BMI}-$ SDS -0.11). Conclusion: Our data underline the effect of children's social setting on the outcome of multidimensional lifestyle intervention. The presence of a high social risk burden is a negative predictor for successful weight loss. Specific therapeutic programs need to be developed for disadvantaged children and adolescents.


Röbl et al.: The Key Role of Psychosocial Risk on Therapeutic Outcome in Obese Children and Adolescents. Results from a Longitudinal Multicenter Study

\section{Introduction}

Obesity in children and adolescents is a challenging health problem. In most developed and developing countries, the prevalence of obesity is increasing $[1,2]$. Some underlying causes are well established. On the basis of genetic predisposition, social and environmental changes leading to a more sedentary lifestyle and an increased consumption of processed food contributed to a general increase of the obesogenic risk in contemporary societies. On the one hand, a lot of individual childhood obesity risk factors such as low meal frequency, long television viewing time, decreased physical activity [3, 4], formula feeding [5], parental overweight $[6,7]$ and smoking during pregnancy have been identified [8]. On the other hand, previous studies identified a significantly higher prevalence of overweight and obesity in families with migration background [9-15], low income [12, 14, 16], children with mental disabilities [1720], and lower parental educational achievement [21]. Population-based representative surveys like the German Health Interview and Examination Survey for Children and Adolescents (KiGGS) as well as preschool data collected by the German federal states illustrate an association of the prevalence of overweight and obesity with migration background and low socio-economic status (SES). 11- to 13-year-old children from migrant families had an obesity prevalence rate of $10 \%$ compared to $6.4 \%$ among their German peers [2]. Differences in obesity prevalence are even more remarkable when stratifying by SES, as only $2.5 \%$ of the children with high SES and $4.7 \%$ with mean SES were obese, compared to $8.9 \%$ of the children with low SES [22]. The latter are more likely to adopt a sedentary lifestyle and unhealthy nutrition than children from families with a higher SES [22-24]. Furthermore, Ness et al. [25] observed a strong association between social gradient and body fat mass, with children from higher social classes having less fat mass than children from the lowest social class, irrespective of other factors.

Childhood obesity and related diseases generate significant morbidity and health care costs. Therefore, the development, implementation, and evaluation of a structured obesity therapy program for children and adolescents are encouraged by health care providers. As expected, the therapeutic outcomes of pediatric obesity programs differ significantly as well. In a systematic review, 64 randomized controlled trials (5,230 participants) were analyzed [26]. Lifestyle interventions focused on physical activity patterns in 12 studies and on diet in 6 studies; 36 studies concentrated on behavior-oriented treatment programs. The most successful programs were shown to be those working with a multidimensional lifestyle intervention including diet, exercise, and implementation of behavior modification principles. While there are limited data to recommend one treatment program as the most effective, this review shows that the outcome of combined behavioral lifestyle interventions (in terms of sustainable weight reduction) is significantly better compared to standard care or self-help [26].

Little is known about individual predictors of successful weight reduction in obese children and adolescents. Some inhibiting factors have been hypothesized to be related to the constancy of overweight-associated problems: parental overweight, older age ( $>12$ years), female gender, low SES, less initial weight loss, and binge eating disorder [27]. Regular participation in specialized sport groups for obese children before enrollment in the obesity program, on the other hand, predict successful outcome [28].

However, the impact of individual social risk factors in obese children (e.g. migration background, low SES, low school achievement) on the outcome of pediatric obesity programs is currently poorly understood since comprehensive analyses are missing. Therefore, our large longitudinal multicenter study tested the hypothesis that obese children and adolescents with low social risk factors have a better therapeutic outcome than obese children and adolescents with high social risk factors. More specifically, our aims were:

- to describe the psychosocial risk of children and adolescents participating in obesity programs; 
Röbl et al:: The Key Role of Psychosocial Risk on Therapeutic Outcome in Obese

- to determine whether the outcome of pediatric obesity programs is related to individual social risk factors;

- to examine whether a clustering of several risk factors occurs;

- to explore whether single and/or multiple social risk factors are predictive of the outcome of weight reduction programs.

\section{Material and Methods}

Study Cohort

Based on the German Guidelines for the Diagnosis and Treatment of Overweight Children and Adolescents (www.a-g-a.de), computer software using the visual FoxPro 9.0 compiler was developed in 1999 (Adipositas-Patienten-Verlaufsdokumentation; APV) for the standardized prospective documentation of children and adolescents receiving specialized obesity care(www.a-p-v.de). Participation in this quality control program is the precondition for certification as an obesity treatment center by the German Obesity Society (Deutsche Adipositasgesellschaft; DAG) and for refunding of treatment costs by health insurances [29]. Anthropometric and metabolic control parameters as well as treatment strategies (multiprofessional team composition and intensity of lifestyle intervention) are documented longitudinally with the aid of this software. Moreover, APV allows the generation of standardized patient reports, local aggregation of data for quality control and supports patient management. Anonymized data are transmitted for central analysis, for which approval has been obtained from the Ethics Committee of the University of Ulm. Each participating center complies with its local ethical and data management guidelines. Inconsistent data are reported back to the centers twice a year for correction. The APV data collection system allowed the establishment of a large data set [30]. 179 centers specialized in pediatric obesity care in Germany (171), Austria (6), and Switzerland (2) participated in this study.

Information on migration background, school education and parents' employment was available for 62,147 children and adolescents. These patients presented at the participating centers between June 1991 and May 2011 for overweight or obesity diagnostic procedures and treatment. Patients with missing data on gender and non-reliable values for weight status were excluded.

Clinical Design

According to the specifications of the Diagnostic Guidelines of the German Working Group of Childhood Obesity (www.a-g-a.de), all enrolled centers ( $\mathrm{n}=179$ ) offered multidimensional lifestyle intervention programs, comprising nutritional counseling, exercise, implementation of behavior modification, and parental training. An intensive training period of 6-24 months was supplemented by a follow-up period of up to 3 years. Generally, patients participated in an educational session and an additional sport class at least once a week for $45 \mathrm{~min}$. Only patients observed for at least 6 months after finishing the obesity program were included in the study $(n=12,305,19,8 \%)$. According to the guidelines, children were weighed without shoes and wearing light underwear, using a calibrated digital scale with a precision of $0.01 \mathrm{~kg}$. The patients' height was measured by means of a statometer with a precision of $0.1 \mathrm{~cm}$. The children's weight and height values were used to calculate BMI $\left(\mathrm{kg} / \mathrm{m}^{2}\right)$. Anthropometric measurements were performed in the beginning of the intervention and at the end of the follow-up period in each participating center (average follow-up time 14 months). BMI values were calculated by dividing children's weight (kg) by their squared height (m). The degree of overweight was quantified using Cole's Box Cox transformation, which normalizes the skewed BMI distribution in childhood and expresses BMI as a standard deviation score $\left(\mathrm{BMI}_{-} \mathrm{SDS}_{\mathrm{LMS}}\right.$ ) [31]. The official reference values were based on the guidelines of the German Obesity Working Group [32].

\section{Social Risk Score}

In order to quantify the social risk for an individual obese child, three categories were aggregated in a summary risk score: migration background, parental employment and school situation of the children [33] (derived from the Hollingshead Social Index, which originally comprised school situation, parental employment, sex, and marital status). The score was established prior to the commencement of the obesity program. The classification encloses the established risk categories for high prevalence of childhood obesity. According to Schenk et al. [10], migration background was defined as: at least one parent immigrated from 
Röbl et al.: The Key Role of Psychosocial Risk on Therapeutic Outcome in Obese

Children and Adolescents. Results from a Longitudinal Multicenter Study

a country outside of Austria, Switzerland, Germany, or Lichtenstein. In terms of school education, children were classified in two groups: children attending regular schools and children attending schools for children with special needs, including children with learning disabilities. Parental employment situation was divided into three groups. By this definition, full-time employment of one parent corresponds to $100 \%$ and half time employment corresponds to $50 \%$. Accordingly, the following categories were developed: at least one parent employed full-time (employment factor 100-200\% in total), no parent full-time employed and at least one working part-time (25-99\%) and marginal employment or unemployment of both parents (0-24\%).

For further classification, the different social risk factors were assessed, and a cumulative social risk score was generated based on the sum of the different risk categories. Three different categories were constructed: low, moderate and high social risk.

\section{Statistical Analysis}

Statistical evaluation was performed using SAS, version 9.1 (SAS Inst. Inc. Cary, NC, USA). The frequency distribution was examined for all parameters. Data are presented as mean $( \pm$ SD) if normally distributed, and median (1st-3rd quartile) if a normal distribution was not present. Nominal data are reported as number and percentage. A probability value of less than 0.05 was considered significant.

To adjust for patient heterogeneity, we used a linear regression model (ANCOVA) with BMI-SDS $\mathrm{LMS}_{\text {as }}$ the dependent variable. The independent variables included in the analysis were: age, gender, treatment duration, initial BMI, and social risk score.

To adjust for multiple comparisons, the Tukey-Kramer method was used.

\section{Results}

12,305 overweight and obese children and adolescents attended a multiprofessional obesity program for 6-24 months and subsequent follow-ups for 6 months up to 3 years (average follow-up 14 months). Participants with short-term interventions and follow-ups of less than 6 months were excluded from the study. The study group did not differ significantly from the entire APV cohort with regard to the cumulative social risk score. The average BMI-SDS at therapy onset in the study group $(2.44 \pm 0.54)$ was very similar to that of the broader APV cohort $(2.42 \pm 0.56)$.

The analysis demonstrated that male patients experienced a significantly higher weight reduction than females ( $\Delta$ BMI-SDS $-0.20 \pm 0.39$ vs. $-0.16 \pm 0.43 ; \mathrm{p}<0.0001$ ). Secondly, patients between 12 and 15 years of age at therapy initiation showed less weight reduction $(\Delta$ BMI-SDS $-0.15 \pm 0.45$ ) when compared to patients under 12 years $(\Delta$ BMI-SDS $-0.19 \pm$ $0.36)$ and patients over 15 years $(\Delta$ BMI-SDS $-0.27 \pm 0.55)(\mathrm{p}<0.0001)$. Thirdly, regarding the degree of obesity, we found a significant difference in weight reduction between the overweight $(\Delta$ BMI-SDS $-0.16 \pm 0.44)$ and the obese group ( $\triangle$ BMI-SDS $-0.18 \pm 0.40)(\mathrm{p}<0.0185)$. No significant difference was found between extremely obese subjects $(-0.18 \pm 0.42)$ and the other two groups.

$1,401(11.4 \%)$ patients live in families with a migration background. Of these, $483(3.9 \%)$ patients had only one parent with migration background, whereas in 918 cases (7.5\%) both parents had a migration background. The weight reduction (expressed as $\triangle$ BMI-SDS) was significantly higher in children and adolescents without migration background $(\triangle$ BMI-SDS $-0.18 \pm 0.42$ ) compared to the group with two-sided migration background ( $\triangle$ BMI-SDS $-0.13 \pm 0.37)(\mathrm{p}<0.0001$; fig. 1$)$.

$95,2 \%(\mathrm{n}=11,714)$ of the parents had an employment factor between 100 and 200\%, $3,2 \%(n=398)$ a part-time employment of at least one parent $(25-99 \%)$ and $1.6 \%(n=193)$ were marginally or not employed. Weight reduction was most successful ( $\Delta$ BMI-SDS $-0.18 \pm$ 0.41 ) in children and adolescents whose parents had an employment factor between 100 and $200 \%$. The mean BMI-reduction was lower ( $\Delta$ BMI-SDS $-0.13 \pm 0.36, \mathrm{p}=0.056$ ) in children and adolescents whose parents were only marginally or not employed (fig. 1). 
Röbl et al.: The Key Role of Psychosocial Risk on Therapeutic Outcome in Obese

Children and Adolescents. Results from a Longitudinal Multicenter Study

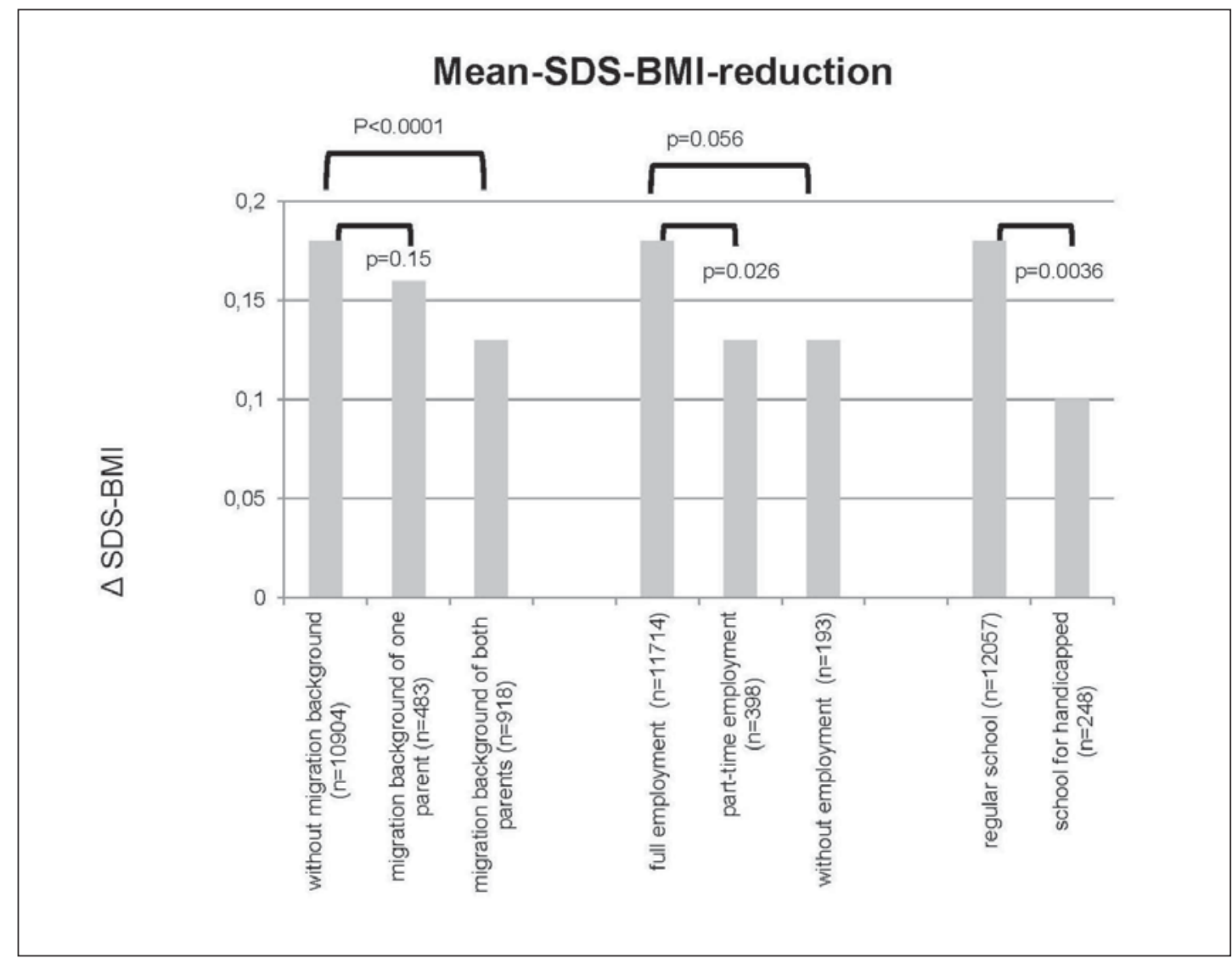

Fig. 1. Mean-BMI-SDS reduction in relation to migration background, employment (parents), and school situation (children).

$98.0 \%(n=12,057)$ of the children and adolescents attended regular schools and $2.0 \%$ $(\mathrm{n}=248)$ schools for children with special needs. The most effective reduction in BMI-SDS $(\Delta$ BMI-SDS $-0.18 \pm 0.41$ ) was achieved by children and adolescents who attended a regular school. The mean BMI-SDS reduction of children and adolescents attending schools for children with special needs was significantly lower $(\Delta$ BMI-SDS $-0.10 \pm 0.42)(p=0.0036$; fig. 1).

Using the cumulative social risk score, $84.4 \%(n=10,387)$ of the children and adolescents had low social risk factors, $13.4 \%(\mathrm{n}=1,655)$ showed moderate risk factors, and $2.1 \%(\mathrm{n}=$ 263) had high risk factors.

Based on a linear regression model (ANCOVA) to adjust for patient heterogeneity, we found that there are significant differences in BMI-SDS reduction between the subgroup with low social risk factors $(\Delta$ BMI-SDS $-0.19 \pm 0.42$ ) and the subgroups with moderate $(\triangle$ BMI-SDS $-0.14 \pm 0.39 ; \mathrm{p}<0.0001$ ) or high social risk ( $\triangle$ BMI-SDS $-0.11 \pm 0.37 ; \mathrm{p}<0.0083$ ) (fig. 2). On the other hand, the intensity of intervention (number of multiprofessional counseling units of $45 \mathrm{~min}$ ) was significantly higher in the group with high social risk (96 units) than in the subgroup with low social risk factors (71 units; $\mathrm{p}<0.0009)$ and in that with moderate social risk factors (86 units; $\mathrm{p}<0.0001$. 
Fig. 2. BMI-SDS reduction and number of therapy units in relation to social risk.
Röbl et al.: The Key Role of Psychosocial Risk on Therapeutic Outcome in Obese Children and Adolescents. Results from a Longitudinal Multicenter Study

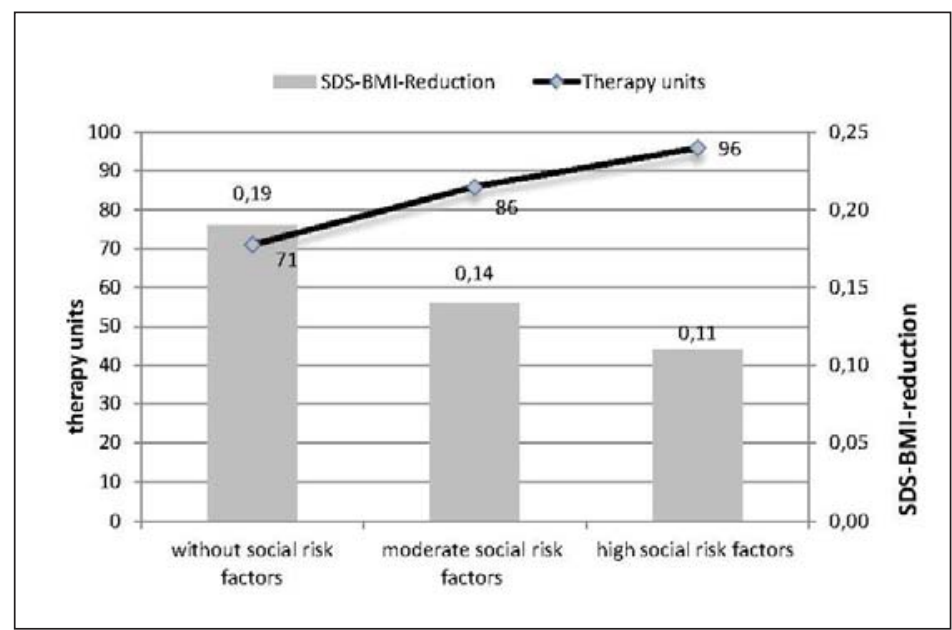

\section{Discussion}

To date, several risk factors associated with childhood obesity have been thoroughly investigated. Various studies demonstrated the influence of migration background $[2,9,10$, $12]$, parental obesity $[6,7]$, short sleep duration, television viewing and physical inactivity [3, 4], low income [12,14], and formula feeding [5] on children's BMI. Unfortunately, the impact of these social risk factors on the outcome of pediatric obesity treatment programs is unknown.

To our knowledge, this is the first large multicenter study analyzing the impact of social risk factors on the outcome of lifestyle intervention programs for obese children. In a randomized controlled trial with 204 obese children, social facilitation was the most effective therapy approach to weight reduction maintenance, but mainly in children with initially low social risk [34]. In the KOPS study, Müller et al. [35] showed in 2006 that middle- or high-class children benefit more from obesity interventions than children with low SES. In contrast, in the study of Braet [27] including 122 children, the degree of overweight, initial weight loss and age, but not the SES, were predictors for weight reduction. In our entire study cohort, $15.6 \%$ of the participating children presented at least one psychosocial risk factor (migration background, parental unemployment, special educational needs). The representative German Health Interview and Examination Survey for Children and Adolescents (KIGGS) showed that $27.2 \%$ of children between 2 and 17 years of age come from families with low SES [36]. Taking this into account, our study cohort displays an unexpectedly low proportion of children with psychosocial risk factors, indicating that socially disadvantaged, obese children and adolescents are less likely to be included in obesity treatment programs.

Furthermore, the KIGGS results showed that migrant children have a two-fold and children with a low social status a three-fold risk of becoming obese when compared to native German children and children with a high social status, respectively [2, 22]. Also, 53.7\% of the children with two-sided migration background (compared to $22.1 \%$ of the children without migration background) belonged to the low SES group [37], thus having a 'double risk' for childhood obesity. In contrast, these patient groups are significantly underrepresented not only in this study cohort (11\%) but also in the entire APV cohort (8.9\%). Based on these results, it could be speculated that multiprofessional pediatric obesity programs are poorly accepted and accessed by high-risk groups for childhood obesity. Some possible reasons should be discussed. For families with low SES and/or migration background, it is more difficult to obtain medical care in general. Language problems further amplify such diffi- 
Röbl et al.: The Key Role of Psychosocial Risk on Therapeutic Outcome in Obese

Children and Adolescents. Results from a Longitudinal Multicenter Study

culties, especially for unemployed mothers in families with migration background. This delay of treatment is related to higher morbidity and increased costs later in life, but may also cause developmental delay during childhood and adolescence. Even extreme obesity is not recognized as a health problem in some high-risk families.

Additionally, pediatric patients' chances of success in an obesity program are significantly influenced by psychosocial risk. Although patients with a high risk score received significantly more therapy units (e.g., multidimensional lifestyle intervention) than patients without psychosocial risk ( $\mathrm{p}<0.0009$ ), the mean BMI-SDS reduction in patients without psychosocial risk was almost double that of patients with a high risk score $(-0.19$ vs. -0.11 ; $\mathrm{p}<0.0083$ ). Unemployment, low education and migration are well-known risk factors for poor health care outcome in adults $[17,38,39]$. In our study, the impact of the abovementioned factors was examined both individually and as a cumulative risk score. Not only the cumulative psychosocial risk score but also single risk components were found to significantly influence the main therapeutic outcome. For instance, obese children of fully employed parents experienced a significantly greater weight loss than obese children of part-time employed parents.

To avoid a bias resulting from different therapeutic settings, our study only included multiprofessional pediatric obesity programs according to the guidelines of the German Working Group of Childhood Obesity (see clinical design). Furthermore, topics and frequency of patient counseling was not significantly different among the participating centers.

It can only be speculated about the reasons for the poorer therapy outcome in the subgroup with high social risk. A potential overburden by cognitive demands, on the one hand, and the lack of parental support during the lifestyle intervention program, on the other hand, might have contributed to the poor outcome reported among these children and adolescents. Furthermore, the expectations of patients and professionals concerning therapy goals and necessary lifestyle changes are often very different, which can result in poor patient engagement in the therapeutic efforts. In terms of diversity management, adapted therapeutic tools had to be developed with respect to the specific characteristics of the risk groups (e.g., their self-efficacy, cultural background, or perceptions of health and illness).

The strengths of our study are the large study sample, the multicenter design, and the analysis conducted under real-life conditions and not under the ideal circumstances of clinical trials. However, some important limitations of the study have to be noted. Firstly, only $19.8 \%$ of all documented children and adolescents were included in the study group because of patient drop-out or missing data during follow-up. Secondly, although the fraction of children with high social risk factors among obese children and adolescents is high in the general population, in our subgroup only $13.4 \%$ showed moderate risk factors and $2.1 \%$ high risk factors. However, no statistically significant difference in terms of social risk factors could be found between the study group and the entire APV cohort.

It thus appears that, although more children with low SES are obese, only few of them have access to a lifestyle intervention program. We therefore assume that only highly motivated children with low SES participate for at least 6 months in lifestyle intervention programs.

In conclusion, our data show that the outcome of multiprofessional lifestyle intervention programs for obese children and adolescents highly depends on social risk factors. In this sense, low SES is a negative predictor for therapy success. Furthermore, there is evidence that children belonging to high-risk groups do not have adequate access to an obesity lifestyle intervention program. New therapeutic concepts need to be developed specifically for obese children and adolescents with low SES. A multilevel approach engaging additional resources such as neighborhood networks and social care centers could be helpful for this large group of obese children and adolescents whose therapeutic needs have not been met so far. 
Röbl et al.: The Key Role of Psychosocial Risk on Therapeutic Outcome in Obese

Children and Adolescents. Results from a Longitudinal Multicenter Study

\section{Acknowledgements}

The APV standardized documentation was supported by grants of the German Obesity Society (DAG) and German Federal Centre for Health Education (BZgA). The APV study group received grant support from the German 'Competence Network Adipositas,' which is initiated by the German Federal Ministry of Education and Research (grant number 01 GI0824; APV-LARGE). We are indebted to all health professionals of the APV Study Group taking care of overweight children and contributing to the APV database, and to Cristina CiupituPlath (Berlin School of Public Health; Berlin, Germany) for her support in editing the manuscript. A list of participating centers has recently been published [30].

\section{Disclosure Statement}

No potential conflicts of interest related to this article were reported.

\section{References}

1 Wang Y, Lobstein T: Worldwide trends in childhood overweight and obesity. Int J Pediatr Obes 2006;1:11-25

-2 Kurth BM, Schaffrath Rosario A: The prevalence of overweight and obese children and adolescents living in Germany. Results of the German Health Interview and Examination Survey for Children and Adolescents (KiGGS) (in German). Bundesgesundheitsbl Gesundheitsforsch Gesundheitsschutz 2007;50:736-743.

-3 Lioret S, Maire B, Volatier JL, Charles MA: Child overweight in France and its relationship with physical activity, sedentary behaviour and socioeconomic status. Eur J Clin Nutr 2007;61:509-516.

4 Jimenez-Pavon D, Kelly J, Reilly JJ: Associations between objectively measured habitual physical activity and adiposity in children and adolescents: systematic review. Int J Pediatr Obes 2010;5:3-18.

5 Armstrong J, Reilly JJ: Breastfeeding and lowering the risk of childhood obesity. Lancet 2002;359:2003-2004.

6 Danielzik S, Pust S, Landsberg B, Muller MJ: First lessons from the Kiel Obesity Prevention Study (KOPS). Int J Obes 2005;29(suppl 2):S78-83.

7 Röbl M, Knerr I, Keller KM, Jaeschke R, Hoffmeister U, Reinehr T, Holl RW: Obesity in children and adolescents and their parents. Correlation of standardized body mass index between patients, their parents and siblings from the multicentre APV data (in German). Dtsch Med Wochenschr 2008;133:2448-2453.

-8 Toschke AM, Ruckinger S, Bohler E, Von Kries R: Adjusted population attributable fractions and preventable potential of risk factors for childhood obesity. Public Health Nutr 2007;10:902-906.

$>9$ Kirchengast S, Schober E: Obesity among female adolescents in Vienna, Austria - the impact of childhood weight status and ethnicity. BJOG 2006;113:1188-1194.

10 Schenk L, Ellert U, Neuhauser H: Children and adolescents in Germany with a migration background. Methodical aspects in the German Health Interview and Examination Survey for Children and Adolescents (KiGGS) (in German). Bundesgesundheitsbl Gesundheitsforsch Gesundheitsschutz 2007;50:590-599.

11 Van Hook J, Balistreri KS: Immigrant generation, socioeconomic status, and economic development of countries of origin: a longitudinal study of body mass index among children. Soc Sci Med 2007;65:976-989.

12 Wang Y, Beydoun MA: The obesity epidemic in the United States - gender, age, socioeconomic, racial/ethnic, and geographic characteristics: a systematic review and meta-regression analysis. Epidemiol Rev 2007;29: 6-28.

13 Duarte-Salles T, Pasarin MI, Borrell C, Rodríguez-Sanz M, Rajmil L, Ferrer M, Pellisé F, Balagué F: Social inequalities in health among adolescents in a large southern European city. J Epidemiol Community Health 2011;65:166-173.

14 Kestila L, Rahkonen O, Martelin T, Lahti-Koski M, Koskinen S: Do childhood social circumstances affect overweight and obesity in early adulthood? Scand J Public Health 2009;37:206-219.

-15 Stamatakis E, Wardle J, Cole TJ: Childhood obesity and overweight prevalence trends in England: evidence for growing socioeconomic disparities. Int J Obes 2005;34:41-47.

16 Brophy S, Cooksey R, Gravenor MB, Mistry R, Thomas N, Lyons RA, Williams R: Risk factors for childhood obesity at age 5: analysis of the millennium cohort study. BMC Public Health 2009;9:467.

17 Reinehr T, Dobe M, Winkel K, Schaefer A, Hoffmann D: Obesity in disabled children and adolescents: an overlooked group of patients. Dtsch Arztebl Int 2009;107:268-275.

18 Batty GD, Deary IJ, Schoon I, Gale CR: Mental ability across childhood in relation to risk factors for premature mortality in adult life: the 1970 British Cohort Study. J Epidemiol Community Health 2007;61:997-1003.

$\checkmark 19$ Emerson E, Robertson J: Obesity in young children with intellectual disabilities or borderline intellectual functioning. Int J Pediatr Obes;5:320-326.

20 Stewart L, Van de Ven L, Katsarou V, Rentziou E, Doran M, Jackson P, Reilly JJ, Wilson D: High prevalence of obesity in ambulatory children and adolescents with intellectual disability. J Intellect Disabil Res 2009;53: 882-886. 
Röbl et al.: The Key Role of Psychosocial Risk on Therapeutic Outcome in Obese Children and Adolescents. Results from a Longitudinal Multicenter Study

21 Lamerz A, Kuepper-Nybelen J, Wehle C, Bruning N, Trost-Brinkhues G, Brenner H, Hebebrand J, HerpertzDahlmann B: Social class, parental education, and obesity prevalence in a study of six-year-old children in Germany. Int J Obes 2005;29:373-380.

22 Kleiser C, Schaffrath-Rosario A, Mensink GB, Prinz-Langenohl R, Kurth BM: Potential determinants of obesity among children and adolescents in Germany: results from the cross-sectional KiGGS Study. BMC Public Health 2009;9:46.

23 Mutunga M, Gallagher AM, Boreham C, Watkins DC, Murray LJ, Cran G, Reilly JJ: Socioeconomic differences in risk factors for obesity in adolescents in Northern Ireland. Int J Pediatr Obes 2006;1:114-119.

24 Oreskovic NM, Kuhlthau KA, Romm D, Perrin JM: Built environment and weight disparities among children in high- and low-income towns. Acad Pediatr 2009;9:315-921.

25 Ness AR, Leary S, Reilly J, Wells J, Tobias J, Clark E, Smith GD; ALSPAC Study Team. The social patterning of fat and lean mass in a contemporary cohort of children. Int J Pediatr Obes 2006;1:59-61.

-26 Oude Luttikhuis H, Baur L, Jansen H, Shrewsbury VA, O’Malley C, Stolk RP, Summerbell CD: Interventions for treating obesity in children. Cochrane Database Syst Rev 2009;1:CD001872.

27 Braet C: Patient characteristics as predictors of weight loss after an obesity treatment for children. Obesity (Silver Spring) 2006;14:148-155.

28 Reinehr T, Brylak K, Alexy U, Kersting M, Andler W: Predictors to success in outpatient training in obese children and adolescents. Int J Obes Relat Metab Disord 2003;27:1087-1092.

-29 Reinehr T, Holl RW, Wabitsch M: The German Working Group of Obesity in Childhood and Adolescence (AGA): improving the quality of care for overweight and obese children in Germany. Obes Facts 2008;1:26-32.

30 Reinehr T, Widhalm K, l'Allemand D, Wiegand S, Wabitsch M, Holl RW: Two-year follow-up in 21,784 overweight children and adolescents with lifestyle intervention. Obesity (Silver Spring) 2009;17:1196-1199.

-31 Cole TJ: The LMS method for constructing normalized growth standards. Eur J Clin Nutr 1990;44:45-60.

32 Kromeyer-Hauschild K, Geller F: Percentiles of body mass index in children and adolescents evaluated from different regional German studies (in German). Monatsschr Kinderheilk 2001;149:807-818.

33 Hollingshead AB: A Four-Factor Index of Social Status. New Haven, Department of Sociology, Yale University, 1975.

34 Wilfley DE, Stein RI, Saelens BE, Mockus DS, Matt GE, Hayden-Wade HA, Welch RR, Schechtman KB, Thompson PA, Epstein LH: Efficacy of maintenance treatment approaches for childhood overweight: a randomized controlled trial. JAMA 2007;298:1661-1673.

-35 Muller MJ, Danielzik S, Landsberg B, Pust S: Interventions to prevent overweight in children. Int J Vitam Nutr Res 2006; 76:225-229.

36 Lampert T, Kurth, BM: Socioeconomic status and health in children and adolescents - results of the German Health Interview and Examination Survey for Children and Adolescents (KiGGS). Dtsch Arztebl Int 2007;104: 342-347.

37 Schenk L, Ellert U: Beschreibung der Kinder mit Migrationshintergrund in KiGGS; in Robert Koch-Institut, Statistisches Bundesamt B (eds): Beiträge zur Gesundheitsberichtserstattung des Bundes: Kinder- und Jugendgesundheitssurvey (KIGGS) 2003-2006, Kinder und Jugendliche mit Migrationshintergrund in DeutschlandBerlin, Robert Koch-Institut, 2008, pp 19-21. Available at http://edoc.rki.de/documents/rki_fv/ reJBwqKp45PiI/PDF/23Ydv84JGTBo6_07.pdf.

38 Govil SR, Weidner G, Merritt-Worden T, Ornish D: Socioeconomic status and improvements in lifestyle, coronary risk factors, and quality of life: the Multisite Cardiac Lifestyle Intervention Program. Am J Public Health. 2009;99:1263-1270.

39 Kuntz B, Lampert T: Socioeconomic factors and obesity. Dtsch Arztebl Int 2010;107:517-522. 